\title{
Nutrition and cellular immunity in hospital patients
}

\author{
By PAULine S. DOWD, J. KELLEHER*, B. E. WALKER \\ AND P.J. GUILLOU \\ Departments of Medicine and Surgery, Clinical Sciences Building, \\ St James's University Hospital, Leeds LS9 $7 T F$
}

(Received 17 September 1985 - Accepted 6 January 1986)

\begin{abstract}
1. The interrelations between nutritional and ccllular immune function measurements were studied in seventy patients suffering from various degrees of malnutrition. They included patients with liver disease, inflammatory bowel disease, neoplastic disease, neurological patients, post-operative surgical patients and patients with respiratory problems.

2. Nutritional measurements included: anthropometry, serum proteins, various vitamins and trace elements, and a prognostic nutritional index (PNI) was calculated.

3. Immunological measurements included: (1) natural killer (NK) cell activity, (2) antibody-dependent cellular cytotoxicity (ADCC), (3) lymphocyte proliferation in response to the mitogens concanavalin $\mathrm{A}$ (Con A), phytohaemagglutinin (PHA) and pokeweed mitogen (PWM) in both $\mathrm{AB}$ and autologous serum.

4. There was no association between anthropometric measurements and tests of immune function.

5. The lymphocyte proliferation in response to mitogenic stimulation in the malnourished patients was depressed in autologous serum compared with the response of the same lymphocytes in pooled $\mathrm{AB}$ serum. The lymphocyte proliferation in response to Con A correlated with transferrin in autologous serum $(r 0.46, n 49$, $P<0.01)$ and to a lesser extent in AB serum $(r 0.33, n 51, P<0.05)$. There was a difference in the Con A-stimulated tritiated-thymidine uptake between patients with low and normal serum zinc levels $(P<0.05)$ for cultures performed in autologous serum, but not $\mathrm{AB}$ serum.

6. There was a significant correlation between NK cell activity and vitamin $\mathrm{C}(r 0.43, n 60, P<0.01)$. There was no relation between nutritional measurements and ADCC or the lymphocyte response to stimulation with PHA or PWM.

7. The results suggest that the severity of overall malnutrition does not influence several different aspects of the cellular immune response. However, the results do suggest that certain individual nutrients, particularly vitamin $\mathrm{C}$ and $\mathrm{Zn}$, do influence the immunoreactivity of different lymphocyte subpopulations.
\end{abstract}

Epidemiological and clinical studies have indicated that nutritional deficiency leads to increased susceptibility to infection (Scrimshaw et al. 1968; Chandra \& Newberne, 1977). This has been most extensively documented in developing countries where malnutrition and infection commonly co-exist. Cellular immunity in particular has been shown to be depressed in children with protein-energy malnutrition (PEM) (Neumann et al. 1975; McMurray et al. 1981). The problem of PEM is also encountered in industrialized countries, particularly in hospital patients. This has been demonstrated in surveys of surgical (Hill et al. 1977), medical (Weinsier et al. 1979) and paediatric patients (Merritt \& Suskind, 1979), for whom measurements of nutritional status were frequently found to be abnormal. An increased incidence of post-operative infections in patients with hypoproteinaemia (Rhoads \& Alexander, 1955) and severe weight loss has been documented (Neumann et al. 1975).

Factors such as age (Chandra et al. 1982), surgical trauma (Law et al. 1974), various types of malignant disease (Johnson et al. 1971), inflammatory bowel disease (Vitorino \& Hodgson, 1980) and liver disease (Zetterman \& Sorrell, 1981) are also associated with immunodepression. These conditions are invariably accompanied by malnutrition, suggesting that the immunodepression and malnutrition may be interrelated.

Studies of the interrelation between malnutrition and immune function in hospital patients are sparse. In one study the body composition of patients was measured using

* For reprints. 
multiple-isotope dilution and immunological function by skin testing in response to five recall antigens (Shizgal, 1981). The body composition of anergic patients was characteristic of malnutrition whereas those who reacted normally had body compositions similar to those of healthy controls. However, a large overlap in results led them to conclude that anergy was not necessarily indicative of malnutrition.

It has been reported that patients with acute PEM and adult marasmus showed depressed total lymphocyte numbers and impaired delayed hypersensitivity responses (Bistrian et al. $1975,1977)$ and suggested that if the weight loss were arrested by nutritional repletion delayed cutaneous hypersensitivity responses returned to normal.

Although these immunological abnormalities may occur as a result of PEM, it is possible that specific micronutrient deficits may be implicated in causing the depressed immune responses (Beisel, 1982). Zinc deficiency in particular has been linked with impaired cellular immunity (Allen et al. 1981). Certain vitamin deficiencies such as vitamin A (Cohen et al. 1979) and vitamin C (Thomas \& Holt, 1978) have also been associated with impaired immunity.

The present study represents an attempt to seek evidence for an interrelation between micronutrient deficiency, PEM and in vitro tests of cellular immunity in a heterogenous group of hospital patients.

\section{EXPERIMENTAL}

\section{Patients}

A total of seventy patients were studied after ethical committee approval had been obtained. Seven separate groups of patients (Table 1) in whom malnutrition might have been expected to occur, were prospectively defined for inclusion in the present study. The varied aetiology of malnutrition in these groups allowed subsequent analysis of results between groups to give some indication of a possible relation between immunity and malnutrition and also the cause of the malnutrition. Fifty of the seventy patients were considered to be malnourished on clinical examination and anthropometric measurements. All of these had two or more abnormally-low levels of the biochemical measurements included in the present study when compared with a young healthy control population. The remaining twenty patients were chosen to provide a normally nourished patient control group and had either a single or no biochemical deficiency when compared with the young healthy control population. This group will subsequently be referred to as the patient control group.

\section{Methods}

A nutritional assessment was performed in all patients and included evaluation of current weight, previous weight, height, mid-arm muscle circumference and triceps skinfold thickness. Mid-arm muscle circumference was derived and results were expressed as percentage ideal using standard tables (Jelliffe, 1966).

Leucocyte vitamin C was determined by the method of Denson \& Bowers (1961). Vitamin A was determined using the fluorometric method of Hanson \& Warwick (1968). Serum Zn and copper were determined by atomic absorption spectrophotometry (Dawson \& Walker, 1969) and serum albumin, transferrin, prealbumin, retinol-binding protein and caeruloplasmin were determined by radial immunodiffusion on agar plates using commercial antisera (Hoechst (UK) Ltd).

Evidence that post-operative morbidity and mortality amongst surgical patients is related to their pre-operative nutritional state has led to the development of a linear equation combining a number of nutritional measurements and is termed the prognostic nutritional index (PNI). The PNI was calculated according to the equation:

$$
\mathrm{PNI}=150-1.66(\mathrm{ALB})-0.78(\mathrm{TSF})-20(\mathrm{TFN}) \text {, }
$$


Table 1. Patient groups studied

\begin{tabular}{|c|c|c|c|c|c|}
\hline \multirow[b]{2}{*}{ Clinical condition } & \multirow[b]{2}{*}{ 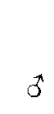 } & \multirow[b]{2}{*}{ q } & \multirow[b]{2}{*}{ Total } & \multicolumn{2}{|c|}{ Age (years) } \\
\hline & & & & Mean & SD \\
\hline Neurological & 9 & 5 & 14 & $61 \cdot 6$ & $14 \cdot 3$ \\
\hline Liver* & 6 & 4 & 10 & $51 \cdot 4$ & 11.5 \\
\hline IBD & 6 & 5 & 11 & $36 \cdot 5$ & $22 \cdot 6$ \\
\hline Elderly & 6 & 4 & 10 & $71 \cdot 0$ & $11 \cdot 1$ \\
\hline Neoplasia $\dagger$ & 9 & 2 & 11 & $71 \cdot 0$ & $13 \cdot 1$ \\
\hline Surgical & 6 & 3 & 9 & $70 \cdot 6$ & 11.0 \\
\hline Respiratory & 3 & 2 & 5 & $66 \cdot 8$ & $8 \cdot 5$ \\
\hline Total & 45 & 25 & 70 & $60 \cdot 4$ & $18 \cdot 5$ \\
\hline
\end{tabular}

IBD, inflammatory bowel disease.

* In the liver disease group, nine had alcoholic cirrhosis and one was jaundiced resulting from chronic hepatitis. $\dagger$ In the neoplastic group, the sites of the neoplasia were as follows: oesophagus $(n 4)$, stomach $(n 2)$, lung $(n 2)$, colon $(n 2)$ and pancreas $(n 1)$.

where ALB is serum albumin ( $\mathrm{g} / \mathrm{l})$, TSF is triceps skinfold (mm) and TFN is serum transferrin $(\mathrm{g} / \mathrm{l})$. This formula is a modification of those previously described (Mullen, 1981; Simms et al. 1982). It has been demonstrated that for patients with a PNI of greater than 40 , the incidence of post-operative complications begins to rise and that all patients with a PNI greater than 60 develop major post-operative complications (Simms et al. 1982).

The statistical methods used were Student's $t$ test for comparing means and correlation coefficient for individual indices, since previous analysis revealed that the data were not significantly skewed. The data were further analysed by stepwise multiple-regression analysis.

\section{Immunological tests}

Blood samples for the assessment of immune function and nutritional studies were collected at the same venepuncture. Peripheral blood lymphocytes were isolated by density-gradient centrifugation on Ficoll Hypaque (Sigma Chemical Co., Poole, Dorset).

Natural killer $(N K)$ cell activity. NK cell activity was measured against the human myeloid cell line K562 as previously described (Guillou et al. 1982). Briefly, target cells $\left(2.5 \times 10^{6}\right.$ in $0.25 \mathrm{ml}$ phosphate-buffered saline $(9 \mathrm{~g}$ sodium chloride $/ \mathrm{l})$ ) were labelled by incubation with $100 \mu \mathrm{Ci}{ }^{51} \mathrm{Cr}$ for $1 \mathrm{~h}$. Labelled cells were washed and suspended in RPMI culture medium supplemented with fetal calf serum $(100 \mathrm{~g} / \mathrm{l})$.

Peripheral blood effector lymphocytes were suspended in RPMI with fetal calf serum at the required concentration and twofold serial dilutions were prepared to test at final effector: target cell values of 100:1, 50:1,25:1 and 12:1. Effector cells were added to the wells of round-bottomed microtitre plates in triplicate in a final volume of $0.1 \mathrm{ml}$. An equal volume of target cells $\left(1 \times 10^{4}\right)$ was added to each well. Plates were incubated for $4 \mathrm{~h}$ in a humidified atmosphere of carbon dioxide $(50 \mathrm{ml} / \mathrm{l})$ at $37^{\circ}$. After the incubation period, $0.1 \mathrm{ml}$ supernatant fraction was removed and counted for gamma emission.

Spontaneous and maximum $\mathrm{Cr}$ release were determined by incubating $1 \times 10^{4}$ target cells with $0.1 \mathrm{ml}$ medium and $0.1 \mathrm{ml}$ detergent respectively. The percentage specific $\mathrm{Cr}$ release $\left(\mathrm{Cr}_{\mathrm{rel}}\right)$ was calculated for each effector: target cell value using the formula:

$$
\% \mathrm{Cr}_{\mathrm{rel}}=\frac{\text { experimental }{ }^{51} \mathrm{Cr}_{\mathrm{rel}}-\text { spontaneous }{ }^{51} \mathrm{Cr}_{\mathrm{rel}}}{\text { maximum }{ }^{51} \mathrm{Cr}_{\mathrm{rel}}-\text { spontaneous }{ }^{51} \mathrm{Cr}_{\mathrm{rel}}} \times 100 .
$$


Antibody-dependent cellular cytotoxicity $(A D C C)$. This was measured against the lymphoblastoid Raji cell line derived from a patient with Burkitts lymphoma. Antiserum was raised in rabbits, heat-activated and stored at $-30^{\circ}$. For the assay, Raji cells were incubated with antibody diluted 1:200 for $30 \mathrm{~min}$. The cells were then coated with ${ }^{51} \mathrm{Cr}$ and the rest of the assay performed as for NK cell activity.

Lymphocyte transformation. Peripheral blood lymphocytes $\left(2 \times 10^{5}\right)$ were cultured in quadruplicate in $0.2 \mathrm{ml}$ culture medium (Dulbecos modified medium supplemented with autologous $(100 \mathrm{ml} / \mathrm{l})$ or $\mathrm{AB}(100 \mathrm{ml} / \mathrm{l})$ serum, 2-mercaptoethanol $(50 \mu \mathrm{mol} / \mathrm{ml})$ and gentamicin $(160 \mu \mathrm{g} / \mathrm{ml})$ ) for $72 \mathrm{~h}$ at $37^{\circ}$ in a humidified atmosphere of $\mathrm{CO}_{2}(50 \mathrm{ml} / 1)$. Mitogens were used at concentrations which had been previously determined as giving optimal responses in controls, concanavalin A (Con A; Miles Laboratories, Slough, Bucks) $8 \mu \mathrm{g} / \mathrm{ml}$, phytohaemagglutinin (PHA; Difco Laboratories, West Molesey, Surrey) diluted $1: 250$, pokeweed mitogen (PWM; Sigma Chemical Co., Poole, Dorset) $10 \mathrm{mg} / \mathrm{l}$. Cultures were pulsed with tritiated thymidine $18 \mathrm{~h}$ before harvesting and counted for $\beta$-emission.

\section{RESULTS}

A breakdown of the patients into those with zero to one, two to three and four or more deficiencies is shown in Table 2. The mean age of the patients grouped in this way did not differ significantly. The distribution of the various clinical conditions between the groups was fairly even. However, there were disproportionately more patients with inflammatory bowel disease in the patient control group and disproportionately less of the elderly-neglected and liver-disease patients were represented in this group.

Table 3 shows the nutritional levels measured in the patient control group and the groups of patients with multiple deficiencies. There was no significant difference in the percentage ideal body-weight when the patients were divided in this manner. Similarly, serum $\mathrm{Cu}$ and caeruloplasmin levels were not significantly different between the three groups. The serum proteins albumin, prealbumin and transferrin were significantly lower in the groups of patients with two to three and those with four or more deficiencies. For all the other nutritional levels there were no significant differences between the groups of patients with zero to one and two to three deficiencies. The group with four or more deficiencies, however, had levels significantly lower than either of these two groups. The PNI calculation was significantly higher in both groups of patients with multiple deficiencies.

\section{Interrelation between immunological function and malnutrition}

Multiple deficiencies. Dividing the patients according to the number of abnormal biochemical measurements did not show any significant differences for NK cell activity, ADCC, or lymphocyte transformation responses to any of the mitogens tested irrespective of the serum used to support the cultures.

$P N I$. In an attempt to discern whether the immunological tests related to the PNI, patients were divided into three groups; those with good $(0-40)$, intermediate $(40-60)$ and poor $(>60)$ PNI values. The distribution of disease groups dividing the patients in this manner is shown in Table 4. The mean ages did not differ significantly between groups. Many of the patients in the group with a PNI less than 40 were the same as those with zero to one deficiencies and similarly for the other two groups. There was, however, a certain degree of patient redistribution to make analysis in these groups worthwhile.

There was no difference in NK cell activity, ADCC or lymphocyte proliferation to any of the mitogens tested dividing the patients in this way. 
Table 2. Distribution of patients according to the number of biochemical deficiencies

\begin{tabular}{|c|c|c|c|c|}
\hline & & \multicolumn{3}{|c|}{ No. of deficiencies } \\
\hline \multicolumn{2}{|c|}{ Clinical condition } & $0-1$ & $2-3$ & $>4$ \\
\hline \multicolumn{2}{|l|}{ Neurological } & 6 & 5 & 3 \\
\hline \multicolumn{2}{|l|}{ Liver } & 1 & 3 & 6 \\
\hline \multicolumn{2}{|l|}{ IBD } & 6 & 2 & 3 \\
\hline \multicolumn{2}{|l|}{ Elderly } & 0 & 6 & 4 \\
\hline \multicolumn{2}{|l|}{ Neoplasia } & 3 & 3 & 5 \\
\hline \multicolumn{2}{|l|}{ Surgical } & 2 & 3 & 4 \\
\hline \multicolumn{2}{|l|}{ Respiratory } & 1 & 2 & 1 \\
\hline \multirow{3}{*}{$\begin{array}{l}\text { Total } \\
\text { Age (years): }\end{array}$} & & 20 & 24 & 26 \\
\hline & Mean & 57.8 & $58 \cdot 1$ & $63 \cdot 8$ \\
\hline & SD & $20 \cdot 7$ & $17 \cdot 9$ & $16 \cdot 6$ \\
\hline
\end{tabular}

IBD, inflammatory bowel disease.

Table 3. Nutritional indices in three groups of patients with zero to one deficiencies (patient control group), two to three deficiencies and four or more deficiencies

(Mean values and standard deviations)

\begin{tabular}{|c|c|c|c|c|c|c|}
\hline \multirow{2}{*}{$\begin{array}{l}\text { Deficiencies... } \\
\text { Nutritional indices }\end{array}$} & \multicolumn{2}{|c|}{$0-1(n 20)$} & \multicolumn{2}{|c|}{$2-3(n 24)$} & \multicolumn{2}{|c|}{$\geqslant 4(n 26)$} \\
\hline & Mean & SD & Mean & $\mathrm{SD}$ & Mean & SD \\
\hline \multicolumn{7}{|l|}{ Serum: } \\
\hline Albumin (g/l) & $34 \cdot 0$ & 5.6 & $28 \cdot 8^{*}$ & $5 \cdot 8$ & $20 \cdot 2^{*} \dagger$ & $5 \cdot 1$ \\
\hline Prealbumin $(g / l)$ & 0.23 & 0.053 & $0 \cdot 168^{*}$ & 0.078 & $0 \cdot 104 * \dagger$ & 0.05 \\
\hline Transferrin $(\mathrm{g} / \mathrm{l})$ & $2 \cdot 65$ & 0.63 & $2 \cdot 16^{*}$ & 0.40 & $1.63^{*+}$ & 0.46 \\
\hline Retinol-binding protein (mg/l) & 47 & 16 & 39 & 19 & $17^{* \dagger}$ & 12 \\
\hline Vitamin A $(\mu \mathrm{g} / \mathrm{l})$ & 602 & 195 & 507 & 193 & $296 *+$ & 171 \\
\hline Zinc $(\mu \mathrm{mol} / \mathrm{l})$ & $13 \cdot 1$ & $3 \cdot 2$ & $11 \cdot 7$ & $2 \cdot 2$ & $10 \cdot 0^{*+}$ & 1.9 \\
\hline Copper $(\mu \mathrm{mol} / \mathrm{l})$ & $21 \cdot 5$ & $5 \cdot 0$ & $20 \cdot 3$ & $6 \cdot 2$ & $21 \cdot 9$ & $5 \cdot 0$ \\
\hline Caeruloplasmin $(\mathrm{g} / \mathrm{l})$ & 0.503 & 0.162 & 0.428 & $0 \cdot 126$ & 0.473 & $0 \cdot 142$ \\
\hline Vitamin $C\left(\mu \mathrm{g} / 10^{8}\right.$ leucocytes $)$ & $20 \cdot 2$ & $4 \cdot 0$ & $18 \cdot 0$ & $7 \cdot 9$ & $11 \cdot 0^{*} \dagger$ & $5 \cdot 4$ \\
\hline Percentage IBW & $91 \cdot 5$ & $20 \cdot 5$ & $85 \cdot 0$ & $24 \cdot 5$ & 90.6 & $24 \cdot 1$ \\
\hline Percentage TSF & $86 \cdot 5$ & $46 \cdot 7$ & $68 \cdot 0$ & $35 \cdot 8$ & $66 \cdot 7$ & $14 \cdot 2$ \\
\hline PNI & $31 \cdot 0$ & $18 \cdot 3$ & $51 \cdot 4^{*}$ & $12 \cdot 1$ & $76 \cdot 5^{*}+$ & $15 \cdot 2$ \\
\hline
\end{tabular}

IBW, ideal body-weight; TSF, triceps skinfold thickness; PNL, prognostic nutritional index.

* Mean values were significantly different from patient control group $(P<0.01)$.

$\uparrow$ Mean values were significantly different from the other two groups $(P<0.01)$.

\section{Immunological function and specific nutritional deficiencies}

$N K$ cell activity. There was a significantly positive correlation between NK cell activity and leucocyte vitamin C levels $(r 0.43, n 60, P<0.01$; Fig. 1$)$. If patients were divided into those with low leucocyte vitamin C levels $\left(<15 \mu \mathrm{g} / 10^{8}\right.$ leucocytes) and those with normal levels ( $>15 \mu \mathrm{g} / 10^{8}$ leucocytes), a significant difference was observed between the two groups and this was true for all the higher effector: target cell values (Fig. 2). The distribution of clinical conditions in these two groups was fairly even (Table 5).

NK cell activity did not correlate with age or any of the other individual nutritional indices measured.

$A D C C$. ADCC did not correlate with any of the individual nutritional factors measured. 
Table 4. Distribution of patients according to prognostic nutritional index* $(P N I)$ value

\begin{tabular}{|c|c|c|c|c|}
\hline \multirow{2}{*}{\multicolumn{2}{|c|}{ Clinical condition }} & \multicolumn{3}{|c|}{ PNI } \\
\hline & & 040 & $40-60$ & $>60$ \\
\hline & 4 & 6 & 4 \\
\hline \multicolumn{2}{|l|}{ Liver } & 2 & 5 & 3 \\
\hline \multicolumn{2}{|l|}{ IBD } & 4 & 5 & 2 \\
\hline \multicolumn{2}{|l|}{ Elderly } & 2 & 3 & 5 \\
\hline \multicolumn{2}{|l|}{ Neoplasia } & 1 & 4 & 5 \\
\hline \multicolumn{2}{|l|}{ Surgical } & 3 & 1 & 5 \\
\hline \multicolumn{2}{|l|}{ Respiratory } & 1 & 3 & 1 \\
\hline \multirow{3}{*}{$\begin{array}{l}\text { Total } \\
\text { Age (years): }\end{array}$} & & 17 & 27 & 26 \\
\hline & Mean & $57 \cdot 2$ & $54 \cdot 9$ & $65 \cdot 6$ \\
\hline & SD & $21 \cdot 0$ & $19 \cdot 7$ & $15 \cdot 6$ \\
\hline
\end{tabular}

IBD, inflammatory bowel disease.

* PNI $=150-1.66(\mathrm{ALB})-0.78(\mathrm{TSF})-20(\mathrm{TFN})$, where ALB is serum albumin ( $\mathrm{g} / \mathrm{l})$, TSF is triceps skinfold thickness $(\mathrm{mm})$ and TFN is serum transferrin $(\mathrm{g} / \mathrm{l})$.

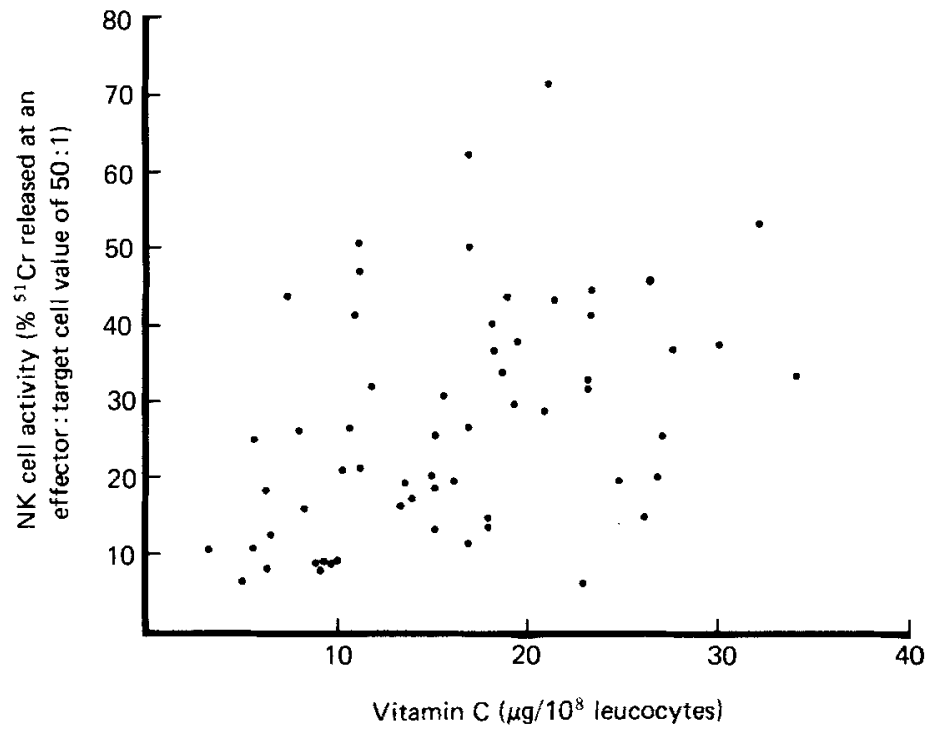

Fig. 1. The relation between natural killer (NK) cell activity and leucocyte vitamin $C, r 0.43$, $P<0.01$.

Lymphocyte transformation. The lymphocyte response to the mitogens PHA and PWM showed no significant correlations with any individual nutritional indices measured in either autologous or AB serum. Several significant correlations were, however, observed in relation to Con $\mathrm{A}$.

The only visceral protein to show any correlation with this response was transferrin and the relation held for autologous serum $(r 0.46, n 49, P<0.01$; Fig. 3$)$ and, to a weaker extent, $\mathrm{AB}$ serum $(r 0.33, n 51, P<0.05)$. When patients were divided into those with low serum transferrin $(<2 \mathrm{~g} / \mathrm{l})$ and those with higher levels, the tritiated thymidine uptake between the two groups was significantly different for cultures performed in autologous serum (Fig. 4) but not for those performed in AB serum. 


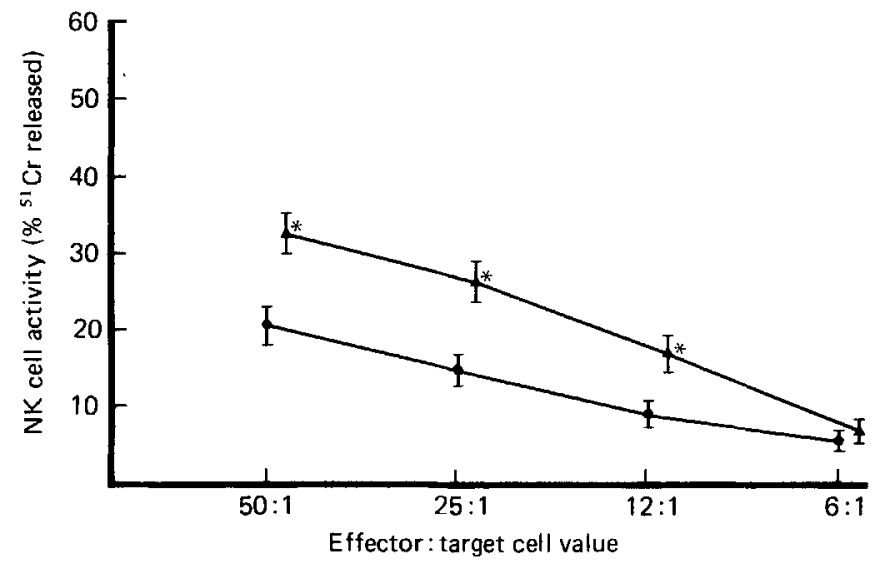

Fig. 2. Natural killer (NK) cell activity in patients with low (O) leucocyte vitamin C ( $<15 \mu \mathrm{g} / 10^{8}$ leucocytes) and normal $(\boldsymbol{A})$ leucocyte vitamin $\mathrm{C}\left(>15 \mu \mathrm{g} / 10^{8}\right.$ leucocytes) for the different effector:target cell values tested. Points are mean values with their standard errors represented by vertical bars. ${ }^{*} P<0.01$.

Table 5. Distribution of patients according to the level of vitamin $C$, transferrin and zinc

\begin{tabular}{|c|c|c|c|c|c|c|}
\hline \multirow{2}{*}{$\begin{array}{l}\text { Clinical } \\
\text { conditions }\end{array}$} & \multicolumn{2}{|c|}{$\begin{array}{c}\text { Vitamin C } \\
\left(\mu \mathrm{g} / 10^{8} \text { leucocytes }\right)\end{array}$} & \multicolumn{2}{|c|}{$\begin{array}{l}\text { Serum transferrin } \\
(\mathrm{g} / \mathrm{l})\end{array}$} & \multicolumn{2}{|c|}{$\begin{array}{l}\text { Serum Zn } \\
(\mu \mathrm{mol} / 1)\end{array}$} \\
\hline & $<15$ & $>15$ & $<2$ & $>2$ & $<11$ & $>11$ \\
\hline Neurological & 6 & 7 & 6 & 8 & 9 & 5 \\
\hline Liver & 3 & 7 & 3 & 7 & 7 & 3 \\
\hline IBD & 3 & 6 & 3 & 6 & 4 & 5 \\
\hline Elderly & 6 & 3 & 4 & 3 & 5 & 2 \\
\hline Neoplasia & 5 & 4 & 4 & 5 & 4 & 5 \\
\hline Surgical & 6 & 3 & 2 & 2 & 2 & 2 \\
\hline Respiratory & 2 & 2 & 0 & 2 & 2 & 0 \\
\hline Total & 31 & 32 & 22 & 34 & 33 & 22 \\
\hline
\end{tabular}

IBD, inflammatory bowel disease.

None of the other nutritional factors showed any correlation with lymphocyte proliferation in response to Con A stimulation. However, when patients were divided into those with low serum $\mathrm{Zn}(<11 \mu \mathrm{mol} / 1)$ and those with levels greater than this, there was a significant difference for cultures performed in autologous serum $(P<0.05$; Fig. 4$)$ but not for cultures performed in AB serum. Again, as shown in Table 5, the distribution of clinical conditions in the groups divided according to their serum transferrin or Zn concentrations were evenly distributed, and there was no obvious disease bias in any of these groups.

The lymphocyte responsiveness to Con A, PHA and PWM showed significant correlations with age, the correlation coefficient being higher when stimulations were performed in autologous serum (Table 6).

The results from -stepwise muiltiple-regression analysis are shown in Table 7. The correlation coefficients and equation of line of best fit were calculated only from patients in whom complete results were available. When some values were missing from an individual patient, that patient's results were rejected from the analysis. This accounts for some slight differences between the results of the correlation coefficients for multiple-regression analysis and correlation coefficients stated elsewhere when all available values were included. 


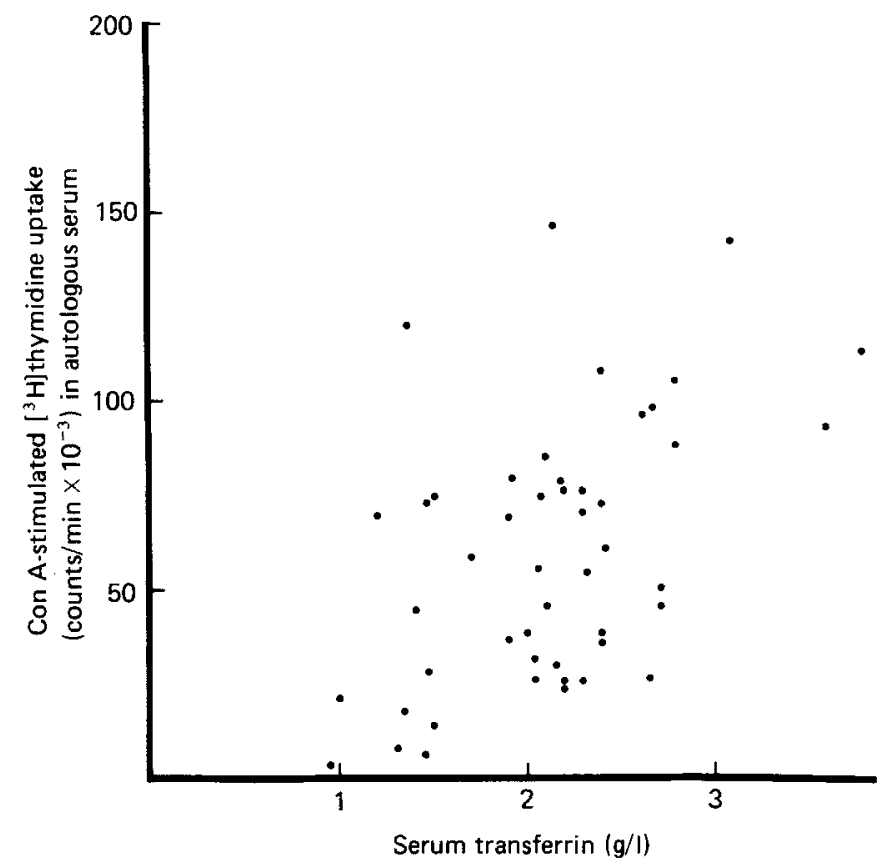

Fig. 3. The relation between lymphocyte transformation in response to concanavalin $A(C o n A)$ and serum transferrin in autologous serum, $r 0 \cdot 46, P<0 \cdot 01$.

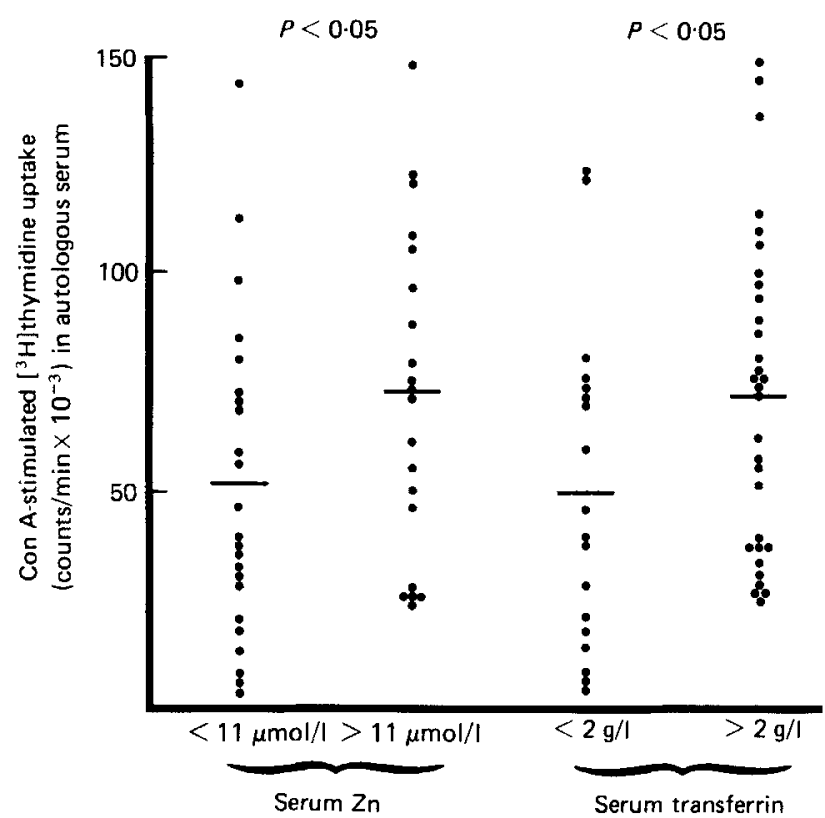

Fig. 4. Lymphocyte proliferation in response to concanavalin $A$ (Con A) in patients with low $(<11 \mu \mathrm{mol} / \mathrm{l})$ and normal serum zinc levels and in patients with low $(<2 \mathrm{~g} / \mathrm{l})$ and normal serum transferrin levels. 
Table 6. Correlation of age and the lymphocyte response to concanavalin $C(C o n A)$, phytohaemagglutinin (PHA) and pokeweed mitogen $(P W M)$ in autologous and AB serum

\begin{tabular}{llccc}
\hline \hline Mitogen & Serum & $r$ & $n$ & $\begin{array}{c}\text { Statistical } \\
\text { significance: } P\end{array}$ \\
\hline Con A & Autologous & 0.43 & 49 & $<0.01$ \\
& AB & 0.38 & 52 & $<0.01$ \\
PHA & Autologous & 0.57 & 49 & $<0.01$ \\
& AB & 0.55 & 52 & $<0.01$ \\
& Autologous & 0.33 & 49 & $<0.05$ \\
& AB & 0.25 & 52 & NS \\
\hline
\end{tabular}

NS, not significant.

Table 7. Calculated correlation coefficients and equations for lines of best-fit using stepwise multiple-regression analysis

\begin{tabular}{|c|c|c|c|c|c|c|c|c|}
\hline \multirow{3}{*}{$\begin{array}{l}\text { Nutritional } \\
\text { indices }\end{array}$} & \multicolumn{8}{|c|}{ Immune function tests } \\
\hline & \multirow{2}{*}{$\begin{array}{l}\text { NK cell } \\
\text { activity }\end{array}$} & \multirow[b]{2}{*}{ ADCC } & \multicolumn{3}{|c|}{ Autologous serum } & \multicolumn{3}{|c|}{ AB serum } \\
\hline & & & Con A & PHA & PWM & Con A & PHA & PWM \\
\hline Albumin & $0 \cdot 04$ & 0.02 & 0.19 & 0.03 & -0.03 & 0.03 & 0.19 & -0.04 \\
\hline Prealbumin & $-0 \cdot 08$ & $-0 \cdot 14$ & -0.21 & $-0 \cdot 25$ & $-0 \cdot 18$ & -0.09 & -0.04 & -0.23 \\
\hline Transferrin & 0.08 & -0.03 & $0.48^{*}$ & $0 \cdot 38^{*}$ & $0 \cdot 12$ & $0 \cdot 35^{*}$ & $0 \cdot 39^{*}$ & $0 \cdot 15$ \\
\hline Retinol-binding protein & $-0 \cdot 13$ & $-0 \cdot 10$ & -0.11 & -0.21 & -0.13 & $-0 \cdot 22$ & 0.04 & $-0 \cdot 13$ \\
\hline Caeruloplasmin & -0.06 & -0.22 & $-0.35^{*}$ & 0.05 & -0.06 & $-0 \cdot 15$ & 0.04 & -0.08 \\
\hline Copper & -0.04 & $-0 \cdot 27$ & -0.28 & 0.09 & -0.03 & -0.03 & -0.02 & $0 \cdot 16$ \\
\hline Zinc & 0.09 & $0 \cdot 19$ & 0.18 & $-0 \cdot 11$ & $-0 \cdot 18$ & -0.03 & $-0 \cdot 10$ & $-0 \cdot 19$ \\
\hline Vitamin A & 0.05 & -0.06 & 0.03 & $-0 \cdot 37^{*}$ & $-0.31^{*}$ & -0.08 & $-0 \cdot 18$ & $-0 \cdot 23$ \\
\hline Vitamin C & $0.31^{*}$ & -0.20 & $0.35^{*}$ & $0 \cdot 10$ & -0.04 & $0 \cdot 21$ & 0.03 & -0.01 \\
\hline
\end{tabular}

NK, natural killer; ADCC, antibody-dependent cellular cytotoxicity; Con A, concanavalin A; PHA, phytohaemagglutinin; PWM, pokeweed mitogen.

Calculated equations for line of best fit: NK cell activity, 16.85+0.65 vitamin C; ADCC, none; Con A (autologous), $44 \cdot 4+0.32$ transferrin -1.16 caeruloplasmin; PHA (autologous), $92 \cdot 1+0.27$ transferrin -0.83 vitamin A; PWM (autologous), 83.3-0.39 vitamin A; Con A (AB serum), 50.0+0.24 transferrin; PHA (AB serum), 73.0 +0.24 transferrin; PWM (AB serum), none. ${ }^{*} P<0.05$.

The overall picture for correlation coefficients was much the same as those previously calculated. However, stepwise multiple-regression analysis revealed a better predicted value for Con A in autologous serum when transferrin and caeruloplasmin were included, the multiple correlation coefficient of 0.67 being slightly better than either transferrin or caeruloplasmin alone ( $r 0.48$ and 0.35 respectively). Whilst Con $\mathrm{A}$ in autologous serum and vitamin $\mathrm{C}$ were significantly correlated $(r 0.35)$, this was rejected by multiple-regression analysis. A similar picture was seen with PHA in autologous serum when the multiple correlation coefficient 0.55 was found using the variables transferrin and vitamin $A$ which, individually, had lower correlation coefficients ( $r 0.38$ and -0.37 respectively).

\section{DISCUSSION}

The existence of both PEM and hypovitaminosis has been demonstrated in hospital patients using a variety of criteria including weight loss, percentage ideal body-weight, arm muscle circumference, triceps skinfold thickness, serum albumin and transferrin, haemoglobin and 
various vitamin levels. Malnutrition using all or some of these indices has been described in patients with inflammatory bowel disease (Harries et al. 1982), liver disease (Morgan et al. 1976), cancer, particularly gastrointestinal malignancies (Dionigi et al. 1980), old age (Morgan et al. 1975) and surgical patients (Hill et al. 1977). In the present study, lower visceral protein, vitamin and trace element levels were found in patients suffering from a variety of these clinical conditions.

\section{Multiple deficiencies}

No simple method exists for assessing the severity of malnutrition in hospital patients. The method of counting the frequency of abnormal nutritional indices usually results in few, if any, patients with no abnormalities at all. Anthropometric measurements are difficult to interpret and in some situations may bear little relation to laboratory nutritional measurements (Dowd et al. 1983). In the present study, nine of the seventy patients had no biochemical abnormalities, and eleven patients had an isolated biochemical deficiency. These two groups combined made a sufficiently large patient control population for comparison with those groups with multiple abnormalities. Patients with two to three deficiencies were considered to be moderately malnourished and those with four or more deficiencies severely malnourished.

The lack of any significant difference in mean NK cell activity, ADCC or lymphocyte transformation in response to mitogens between groups with increasing numbers of deficiencies suggests that the severity of malnutrition does not adversely affect these particular cellular functions.

\section{PNI}

An alternative method of grouping the patients was attempted. Various methods have been devised to combine several nutritional measurements as pre-operative indicators of nutritional status. The PNI, combining serum albumin and transferrin, and the triceps skinfold thickness devised by Mullen (1981) and further modified by Simms et al. (1982), was used. This index has been shown to be a useful pre-operative indicator of postoperative mortality (Simms et al. 1982) and has also been shown to relate to prognosis in critically ill medical patients (Eisenberg et al. 1981). The immunological tests measured in these patients showed no relation with the PNI values. These aspects of cellular immunity do not explain the prognostic value of these nutritional measurements.

\section{NK cell activity}

NK cell activity in the present study did show a significant correlation with leucocyte vitamin $C$ but not with any of the other nutritional indices measured, but the relation was not close and suggests that other factors were also influencing this assay of cytotoxic function. The inherent day-to-day variability of the NK assay may explain some of this scatter and the relation with vitamin $\mathrm{C}$ status may be improved if mononuclear cell vitamin $\mathrm{C}$ is assayed rather than total leucocyte plus platelet levels as used in the present study.

A study of NK cell activity in malnourished children suggested that NK cell activity was impaired. However, the large scatter and skewed distribution of these results and the lack of nutritional information make it impossible to draw any firm conclusions from this work (Salimonu et al. 1982).

NK cell activity has previously been shown to be low in post-operative surgical patients (Guillou et al. 1982). In this group, activity returns to normal within $72 \mathrm{~h}$ and all of our post-operative patients were studied at least $5 \mathrm{~d}$ post-operatively. Although it would appear that NK cell function is related to the leucocyte vitamin C levels, it is unlikely that this is the only factor influencing this assay of cytotoxic function. 


\section{$A D C C$}

A decrease in ADCC has been shown in critically ill surgical patients which indicates the severity of illness and is useful in predicting prognosis (McCredie, 1980). However, in the present study, ADCC showed no relation with the PNI or with any other nutritional factor.

\section{Lymphocyte proliferation}

Lymphocyte blastogenic responses to the mitogens Con A and PHA correlated significantly with age, the response decreasing with age. This depression of response with increasing age has been previously documented (Hallgren \& Buckley, 1973). However, the present study did show that factors other than age may influence this response.

The responses to Con A revealed a number of relations which were not observed in response to stimulation with the mitogens PHA or PWM. Presumably, if age was the factor most influencing these responses, PHA and PWM would have shown similar relations. Con $\mathrm{A}$ has been previously reported as detecting defects not observed by PHA responses in both cancer patients (Golub et al. 1974) and patients with major burns (Munster et al. 1980). Con A and PHA are both T-cell activators, therefore similar results would be expected. However, work in mice has suggested that Con A and PHA may activate different T-cell subpopulations (Stobo \& Paul, 1973). It is possible that T-cell subsets stimulated by Con $\mathbf{A}$ are differentially affected in a variety of clinical conditions and in undernutrition.

The serum of patients with alcoholic liver disease has been shown to reduce the transformation response of normal lymphocytes indicating the presence of a serum inhibitory factor (Zetterman \& Sorrell, 1981). However, our findings suggest that liver patients are not unique in demonstrating this phenomenon. The sometimes very-large difference in stimulation between cultures performed in autologous and in $A B$ serum may be a consequence of circulating serum inhibitors or the lack of a vital serum component required for optimal lymphocyte transformation. Children with PEM have been shown to exhibit depressed in vitro lymphocyte transformation in autologous serum (Moore et al. 1977; Beatty \& Dowdle, 1979) and one such study carried out mixing-experiments which suggested that kwashiorkor serum lacked factors present in normal serum that are required for optimal lymphocyte blastogenesis (Beatty \& Dowdle, 1979).

In the present study the percentage change in stimulation from autologous to AB serum was significantly different between the group of patients with zero to one deficiency and those with four or more deficiencies. This suggests that there may be a nutritional cause. Dividing the patients on the basis of the PNI gave a clearer separation, with the patient groups having a PNI greater than 40 showing larger enhancement of responses in AB serum. This suggests that it may be protein factors which are lacking from the serum as the PNI calculation is based on albumin and transferrin values.

Albumin did not show any relation with Con A stimulation in either autologous or $\mathrm{AB}$ serum. However, serum transferrin did show a significant correlation with Con A-stimulated lymphocyte proliferation in autologous serum and a much weaker correlation in AB serum.

There is evidence to suggest that the $\mathrm{Zn}$ content of serum in which transformation is carried out is important for determining the extent of the response. A $40-60 \%$ reduction in transformation on removal of $\mathrm{Zn}$ from the culture media and serum has been demonstrated (Messer et al. 1982).

Although the serum $\mathrm{Zn}$ in the patients studied did not correlate with Con A-stimulated lymphocyte transformation, patients with serum $\mathrm{Zn}$ levels less than $11 \mu \mathrm{mol} / 1 \mathrm{did}$ show significantly lower responses in autologous serum compared with those with higher $\mathrm{Zn}$ levels. This difference was insignificant for cultures performed in AB serum. The AB serum 
was subsequently found to have a high- $\mathrm{Zn}$ content $(19.4 \mu \mathrm{mol} / \mathrm{l})$ and this may account for the lack of difference in normal serum.

$\mathrm{Zn}$ uptake by blasting cells may be closely linked to transferrin. Phillips (1978) demonstrated that in serum-free cultures of several $\mathrm{Zn}$ compounds tested, including $\mathrm{Zn}$ albumin, $\mathrm{Zn}$ transferrin was the only one capable of stimulating tritiated thymidine uptake in PHA-stimulated peripheral blood lymphocytes beyond that produced by PHA alone. It would therefore seem likely that transferrin levels could also limit transformation by decreasing the carrier-bound $\mathrm{Zn}$ available for lymphocyte activation. There was a weak correlation between transferrin and $\mathrm{Zn}(r 0.4, n 68, P<0.05)$ but it is not known how much of the $\mathrm{Zn}$ in any patient is bound to transferrin and the mechanism by which $\mathrm{Zn}$ regulates in vitro lymphocyte transformation is not yet understood.

While vitamin $\mathrm{C}$ deficiency showed a significant relation with lymphocyte blastogenesis in response to Con A stimulation, this relation was rejected by stepwise multiple-regression analysis which suggested a better predicted value using a combination of transferrin and caeruloplasmin. This result for vitamin C differs from the results of Neumann et al. (1975) who found a significant correlation between vitamin $\mathrm{C}$ levels and response to PHA in malnourished children. However, a study on experimentally deprived human subjects failed to show any decrease in response to the mitogen PHA (Kay et al. 1982).

Looking for a relation between nutrition and cellular immune response in a study such as this is hampered by the possibility that other factors apart from malnutrition may be responsible for producing diminished immunocompetence. Amongst such factors are the disease itself, liver disease, neoplastic disease and inflammatory bowel disease which may be associated with depressed immunocompetence (Victorino \& Hodgson, 1980; Mullin \& Kirkpatrick, 1981 ; Zetterman \& Sorrell, 1981). Other factors to be considered include drugs, and especially steroids (Skinner \& Schwartz, 1972). None of the patients included in the present study was receiving steroids but the effect of other drugs was not controlled. In the present study, an attempt to exclude the influence of disease was made by comparing the malnourished patients with well-nourished patients with similar diseases. There was, however, a somewhat uneven distribution of disease conditions in the different groups. When the patients are divided on the basis of single nutrient abnormalities, the distribution of the disease conditions in the separate groups is more even. While this does not definitely exclude the influence of the disease itself on the immune indices measured it does, to some extent, implicate the single nutrients $\mathrm{Zn}$ and vitamin $\mathrm{C}$ as factors which influence immunocompetence in hospital patients.

In summary, these results fail to demonstrate that overall malnutrition is associated with depression of several different aspects of the cellular immune response. However, our findings suggest that subnormal levels of certain individual nutrients, such as $\mathrm{Zn}$ and vitamin $\mathrm{C}$, may influence the immunoreactivity of different lymphocyte subpopulations. Further investigation using more specific methods for cellular $\mathrm{Zn}$ and vitamin $\mathrm{C}$ concentration may further explain the importance of these two nutrients in regulating cellular immunity.

The authors would like to thank Mrs D. Homer, Miss H. Field and Mrs C. W. Ramsden for technical assistance. P.S.D. is supported by the Manny Cussins Research Fellowship, jointly administered by the West Riding Medical Research Trust and the British Digestive Diseases Foundation. 
Bistrian, B. R., Blackburn, G. L., Scrimshaw, N. S. \& Flatt, J. P. (1975). American Journal of Clinical Nutrition 28, $1148-1155$.

Bistrian, B. R., Sherman, M., Blackburn, G. L., Marshall, R. \& Shaw, C. (1977). Archives of Internal Medicine 137, 1408-1411.

Chandra, R. K., Joshi, P., Au, B., Woodford, G. \& Chandra, S. (1982). Nutrition Research 2, 223-232.

Chandra, R. K. \& Newberne, P. M. (1977). Nutrition, Immunity and Infection, Mechanisms of Interaction. New York: Plenum Press.

Cohen, B. E., Gill, G., Cullen, P. R. \& Morris, P. J. (1979). Surgery, Gynaecology \& Obstetrics 149, 658-662.

Dawson, J. B. \& Walker, B. E. (1969). Clinica Chimica Acta 26, 465475.

Denson, K. W. \& Bowers, E. F. (1961). Clinical Science 21, 157-162.

Dionigi, P., Dionigi, R., Nazari, S., Bonoldi, A. P., Griziotti, A., Pavesi, F., Tibaldeschi, C., Cividini, F. \& Gratton, I. (1980). Journal of Parenteral and Enteral Nutrition 4, 351-356.

Dowd, P. S., Kelleher, J., Walker, B. E. \& Guillou, P. J. (1983). Clinical Nutrition 2, $79-83$.

Eisenberg, D., Silberman, H., Marynuik, J., Shoffler, R. \& Weiss, J. (1981). Surgical Forum 32, 109-111.

Golub, S. H., O'Connell, T. S. \& Morton, D. L. (1974). Cancer Research 34, 1833-1837.

Guillou, P. J., Hegarty, J., Ramsden, C., Davison, A. M., Will, E. J. \& Giles, G. R. (1982). Transplantation 33, 414-421.

Hallgren, H. M. \& Buckley, C. E. (1973). Journal of Immunology 111, 1101-1 107.

Hanson, J. L. \& Warwick, W. J. (1968). American Journal of Clinical Pathology 50, 525-529.

Harries, A. D., Jones, L. A., Heatley, R. V. \& Rhodes, J. (1982). Human Nutrition: Clinical Nutrition 36 C, 307-313.

Hill, G. L., Blackett, R. L., Pickford, I., Burkinshaw, L., Young, G. A., Warren, J. V., Schorah, C. J. \& Morgan, D. B. (1977). Lancet i, 689-692.

Jelliffe, D. B. (1966). WHO Monograph Series no. 53. Geneva: WHO.

Johnson, M. V., Mailbach, H. I. \& Salmon, S. E. (1971). New England Journal of Medicine 284, $1255-1257$.

Kay, N. E., Holloway, D. E., Hutton, S. W., Bone, N. D. \& Duane, W. C. (1982). American Journal of Clinical Nutrition 36, 127-130.

Law, D. K., Dudrick, S. J. \& Abdou, N. I. (1974). Surgery, Gynecology \& Obstetrics 139, 257-266.

McCredie, J. A. (1980). Surgery 88, 544-550.

McMurray, D. N., Loomis, S. A., Casazza, L. J., Rey, H. \& Miranda, R. (1981). American Journal of Clinical Nutrition 34, 68-77.

Merritt, R. J. \& Suskind, R. M. (1979). American Journal of Clinical Nutrition 32, 1320-1325.

Messer, H. H., Murray, E. J. \& Goebel, N. K. (1982). Journal of Nutrition 112, 652-657.

Moore, D. L., Heyworth, B. \& Brown, J. (1977). Immunology 33, 777-785.

Morgan, A. G., Kelleher, J., Walker, B. E. \& Losowsky, M. S. (1975). International Journal of Vitamin and Nutrition Research 15, 448-462.

Morgan, A. G., Kelleher, J., Walker, B. E. \& Losowsky, M. S. (1976). Gut 17, 113-118.

Mullen, J. L. (1981). Surgical Clinics of North America 16, 465-488.

Mullin, T. J. \& Kirkpatrick, J. R. (1981). Surgery 90, 610-615.

Munster, A. M., Winchurch, R. A., Birmingham, W. J. \& Keeling, P. (1980). Annals of Surgery 192, $772-775$.

Neumann, C. G., Lawlor, G. J., Stiehm, E. R., Swenseid, M. E., Newton, C., Herbert, J., Ammann, A. J. \& Jacob, M. (1975), American Journal of Clinical Nutrition 28, 89-104.

Phillips, J. L. (1978). Cellular Immunology 35, 318-329.

Rhoads, J. E. \& Alexander, L. E. (1955). Annals of the New York Academy of Science 63, 268.

Salimonu, L. S., Ojo-Amaize, E., Williams, A. I. O., Johnson, A. O. K., Cooker, A. R., Adekunle, F. A., Alm, G. V. \& Wigzell, H. (1982). Clinical Immunology and Immunopathology 24, 1-7.

Scrimshaw, N. S., Taylor, L. E. \& Gordon, J. E. (1968). WHO Monograph Series no. 57. Geneva: WHO.

Shizgal, H. M. (1981). Surgery Annual 13, 15-29.

Simms, J. M., Smith, J. A. R. \& Woods, H. F. (1982). Clinical Nutrition 1, 71-79.

Skinner, M. D. \& Schwartz, R. S. (1972). New England Journal of Medicine 287, 221-227.

Stobo, J. D. \& Paul, W. E. (1973). Journal of Immunology 110, 362-375.

Thomas, W. R. \& Holt, P. G. (1978). Clinical and Experimental Immunology 32, 370-379.

Vitorino, R. M. M. \& Hodgson, H. J. F. (1980). Clinical and Experimental Immunology 41, 156-165.

Weinsier, R. L., Hunker, E. M., Krumdieck, C. L. \& Butterworth, C. E. (1979). American Journal of Clinical Nutrition 32, 418-426.

Zetterman, R. K. \& Sorrell, M. F. (1981). Gastroenterology 81, 616-624. 